Research Article

\title{
Effect of Home Bleaching Agents on The Surface Hardness Of Flowable Bulk Fill Resin Composite
}

\section{DWITA ANGESTI', PRIYAWAN RACHMADI ${ }^{*}$, ANITA YULIATI}

'Undergraduate Student of Dental Medicine, Faculty of Dental Medicine, Universitas Airlangga

Surabaya - Indonesia

${ }^{2}$ Department of Dental Material, Faculty of Dental Medicine, Universitas Airlangga Surabaya Indonesia

*Corresponding Author

Email ID: rachmadipri@gmail.com

Received: 25.04.20, Revised: 10.05.20, Accepted: 01.06.20

\begin{abstract}
Background: Composite resins have disadvantages such as low hardness level, shrinkage, and micro-leakage. In the case of deep cavity restorations, bulk-fill composite resins have begun to be used because they facilitate the restoration work and make the restoration time shorter.

Purpose: This study was used to determine whether home bleaching treatment using hydrograph peroxide and carbamide peroxide can reduce the surface hardness of flowable bulk-fill composite resins.

Methods: The research sample is cylindrical with a diameter of $5 \mathrm{~mm}$ and a height of $2 \mathrm{~mm}$, this study was divided into 3 groups. Then each group was measured by Vickers Hardness Tester.

Results: In the One Way Anova test the value of $p=0.020$ was obtained. This indicates a significant difference in the surface hardness of bulk-fill flowable composite resins and a Post hoc test - Tukey HSD must be performed.
\end{abstract}

Conclusion: The results show that hydrogen peroxide home bleaching agent can significantly reduce the surface hardness of bulk-fill flowable composite resins

Keywords: Surface hardness, flowable bulk fill resin composite, home bleaching agents

\section{INTRODUCTION}

The development of dental restorative material with teeth-like colors has been very rapid in the last 55 years. In 1960 Bowen discovered a new material, namely composite resin. The main compound was bisphenol-A glycidyl dimethacrylate (Bis-GMA) ${ }^{[1]}$.

Currently composite resins have been chosen because these materials have a good color, and hardness, which is good enough as a dental restoration material. However, composite resins have disadvantages such as low hardness level, shrinkage, and micro-leakage. Several attempts were made to overcome these problems. Coupling agents are also added to obtain stronger restoration results and no shringkage ${ }^{[1]}$. In the case of deep cavity restorations, bulk-fill composite resins have begun to be used because they facilitate the restoration work and make the restoration time shorter. Nowadays, bulk-fill composite resins are being developed to obtain better curing and polymerization ${ }^{[2,3]}$, and to reduce shrinkage ${ }^{[4]}$.

One of the developments in bulk-fill composite resins currently marketed is bulk flow fill resins with low flow (flowable) and low shringkage. This new innovation is expected to enable bulkfill composite resins able to polymerize optimally ${ }^{[5]}$. According to the chemical changes of the monomer, the flowable bulk-fill composite resin modifies the Bowen monomer (Bis-GMA: 2,2-bis [4- (2- hydroxy-3methacryloxypropoxy) phenyl] propane) to obtain low viscosity ${ }^{[6]}$.

Some efforts have been made by the community ranging from maintaining oral and dental hygiene by brushing teeth, reducing food that can cause stains, and getting teeth-bleaching to achieve a better aesthetic. Nowadays, bleaching is the community's choice to make teeth look brighter because it is considered fast and effective at presenting results. The use of bleaching was first introduced to whiten teeth in 1870 with a classification based on the condition of vital and non-vital teeth or based on the procedures used, in office and home bleaching. In 1990 home bleaching began to be introduced and gained a lot of interest. Its application is relatively easier, costs are more affordable $^{[7]}$, and the safety of the material has a high level of success ${ }^{[8]}$.

An increase in public demand for whitening teeth makes the development of teeth whitening materials become rapid. The vital teeth whitening technique was first introduced by Haywood and Heymann (1989) using a nightguard with 10\% carbamide peroxide. There are currently 2 
external teeth whitening agents, hydrogen peroxide and carbamide peroxide. The whitening ingredients can be used in home bleaching procedures with low concentrations (10-15\% carbamide peroxide) or in office bleaching with higher concentrations $\quad 35 \%$ carbamide peroxide $)^{[9]}$.

The problem arises because the content contained in the bleaching material can affect several mechanical properties of dental restorations such as amalgam, porcelain, glass ionomer cement, compomer, and composite resin ${ }^{[10-12]}$. Bleaching material can oxidize composite resins due to the presence of residual $\mathrm{H}^{2} \mathrm{O}^{[13]}$.

This can reduce the level of surface hardness of the composite resin required, especially for posterior tooth restoration ${ }^{[14]}$. This study was used to determine whether home bleaching treatment using hydrograph peroxide and carbamide peroxide can reduce the surface hardness of flowable bulk-fill composite resins.

\section{MATERIAL AND METHOD}

The sample used was a sample in the form of a flowable bulk-fill composite resin brand Filtek ${ }^{\mathrm{TM}}$ Bulkfill Flowable Restorative (3M ${ }^{\mathrm{T}}{ }^{\mathrm{M}}$ ESPE ${ }^{\mathrm{T} M}$ A3 Shade). The research sample is cylindrical with a diameter of $5 \mathrm{~mm}$ and a height of $2 \mathrm{~mm}$, which meets the research criteria, ie the sample is not porous, the top and bottom are parallel, flat and flat.

This study was divided into 3 groups including 1 control group namely Filtek ${ }^{\mathrm{T} M}$ Bulkfill Flowable Restorative (3M ${ }^{\mathrm{TM}}$ ESPE ${ }^{\mathrm{T}}$ A3 Shade) bulk-fill composite resin with $5 \mathrm{~mm}$ diameter and $2 \mathrm{~mm}$ height without home bleaching agents hydrogen peroxide or carbamide peroxide and 2 treatment groups namely Filtek ${ }^{\mathrm{TM}}$ Bulkfill Flowable Restorative (3M ${ }^{\mathrm{T} M}$ ESPE ${ }^{\mathrm{TM}}$ Shade) bulk-fill composite resin with a diameter of $5 \mathrm{~mm}$ and a height of $2 \mathrm{~mm}$ were given home bleaching agent hydrogen peroxide for 20 minutes per day for 5 days and home administration carbamide peroxide bleaching agent for 120 minutes per day for 5 days.
Pre-making a sample with a flowable bulk-fill composite resin which is inserted into the sample mold to the full using a plastic filling instrument. The mold is then covered with a glass cover and given a weight of $1 \mathrm{~kg}$ for 5 minutes. The load is lifted and the flowable bulk-fill composite resin is illuminated using visible light curing with the tip of the visible light curing tip attached to the glass cover for 40 seconds. After setting then the sample is then put into a desiccator and stored in an incubator for 24 hours at a temperature of 37 degrees.

Group I consisting of 10 flowable bulk-fill type composite resin samples that were immersed in artificial saliva for 60 minutes without bleaching treatment (control group); Group II consisted of 10 flowable bulk-fill composite resin samples which were immersed in artificial saliva for 60 minutes, washed using flowing distilled water for 1 minute. Dry, then soaked with bleaching agent (hydrogen peroxide) for 20 minutes; Group III consisted of 10 bulk fill flowable composite resin samples that were immersed in artificial saliva for 60 minutes washed using flowing distilled water for 1 minute and dried, then soaked with a bleaching agent (hydrogen peroxide) for 120 minutes. Samples were washed again using flowing aquades for 1 minute. Then each group was measured by Vickers Hardness Tester.

\section{RESULT}

The data that has been obtained is then processed and analyzed to find an analysis of whether there are significant differences between treatment groups. The data is obtained by measuring the length of the pyramid-shaped indentation diagonal on the basis of a quadrilateral using a microscope. Then the Vickers Hardness Tester automatically processes the data and the surface hardness values are obtained in Hardness Vickers or Vickers Hardness Number (HV / VHN) units. Each sample is done once indentation test every day for 5 days. Fiffy indentations are obtained and the average is then taken. 
Dwita Angesti et al / Effect Of Home Bleaching Agents On The Surface Hardness Of Flowable Bulk Fill Resin Composite

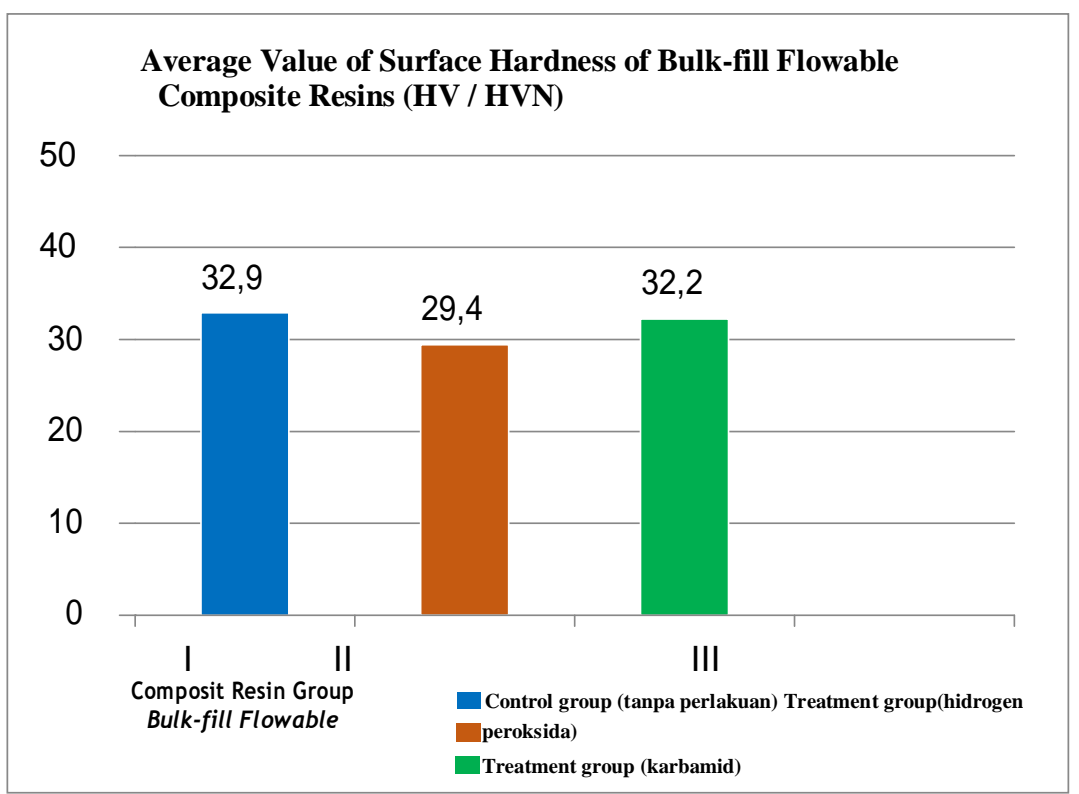

Fig.1: Difference in mean value of surface hardness of bulk-fill flowable composite resin immersed in home bleaching agents and without intervention.

The research data shows that the lowest surface hardness value is group II (29.40 HV / VHN) and the highest is group I (32.90HV / VHN). To test the differences in surface hardness between groups can be done after testing the data distribution using the normality test with the Kolmogorov Smirnov Test and the variant homogeneity test with the Levene Test.

Table 1:Normality Test (Kolmogorov-Smirnov Test)

\begin{tabular}{|l|l|}
\hline \multicolumn{1}{|c|}{ Group } & p-value \\
\hline I (Control) & 0,995 \\
\hline II (Hydrogen peroxide) & 0,469 \\
\hline III (Carbamid peroxide) & 0,458 \\
\hline
\end{tabular}

Footnotes: Normal $=p>0,05$

In the normality test it was found that all groups had a significance value greater than 0.05 ( $p>$ $0.05)$. This shows that the data can be assumed to be normally distributed data. Homogeneity test of variant data uses Levene Test to obtain

homogeneous variant of data between groups. In the homogeneity test, the $p$ value is greater than 0.05 ( $p>0.05)$, that is $p=0.117$, which means the variance of data between homogeneous groups.

Table 2: One Way ANOVA Analysis Result

\begin{tabular}{|l|c|c|c|l|l|}
\hline & Sum of Squares & \multicolumn{1}{l|}{$\mathrm{df}$} & Mean Square & $\mathrm{F}$ & Sig. \\
\hline Between Groups & 70,859 & 2 & 35,429 & 4,533 & 0,020 \\
\hline Within Groups & 211,020 & 27 & 7,816 & & \\
\hline Total & 281,879 & 29 & & & \\
\hline
\end{tabular}

In the One Way Anova test the value of $p=$ 0.020 was obtained. This indicates a significant difference in the surface hardness of bulk-fill flowable composite resins and a Post hoc test Tukey HSD must be performed. 
Table 3: Post Hoc Test-Tukey HSD Results

Footnotes:

$$
\begin{array}{ll}
\mathrm{B} & =\text { Significant } \\
\mathrm{TB} & =\text { Not-significant }
\end{array}
$$

The results of the surface hardness value of the bulk-fill flowable composite resin control group were not significantly different from the groups treated with carbamide peroxide home bleaching agent, but there were significant differences in the groups treated with hydrogen peroxide home bleaching agent. The hardness value of flowable bulk-fill composite resin treated with hydrogen peroxide home bleaching agent was significantly different from the carbamide peroxide home bleaching agent group.

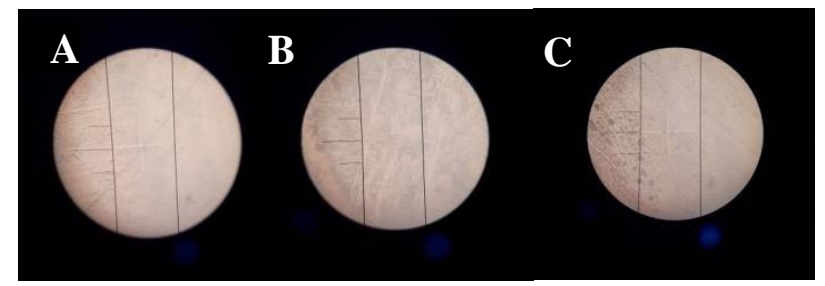

Fig.2: Microscopic surface presentation of flowable bulk-fill composite resin. Presented using

\section{Vickers Hardness Tester.}

The results of the research that have been carried out, the results obtained in the form of a microscopic image of the flow-group flowable bulk-fill composite control group, flowable bulkfill composite resin after being treated home bleaching agent hydrogen peroxide, and flowable bulk-fill composite resin after being given a home bleaching agent carbamide peroxide. Figure $A$ shows flowable bulk-fill composite resin without treatment (control), Figure B with flowable bulk-fill composite resin after being treated with hydrogen peroxide home bleaching agent, and Figure $C$ is flowable bulk-fill composite resin after being treated with carbamide home bleaching agent peroxide.

\section{DISCUSSION}

This research uses flowable bulk-fill composite resins because many are chosen based on their characteristics which can be used for restoration up to $4 \mathrm{~mm}$ and are easy to manipulate ${ }^{[15]}$. Mix the home bleaching agent hydrogen peroxide for 20 minutes and carbamide peroxide for 120 minutes according to the manufacturer's rules. The surface hardness test used is the Vickers Hardness test. This test is used to see the surface hardness of the material. Vickers Hardness Test uses a diamond indenter in the form of a 1360 rectangular pyramid. This indenter compresses the surface of the restoration material with a certain load. The indenter will produce squares of squeeze ${ }^{[16]}$. This study used a load of $200 \mathrm{gram}$ for 10 seconds to see the surface hardness on the surface of the composite resin. The burden used is not too large to get the correct results. If the load is too large, the indenter presses deeper so that the resulting surface hardness is not due to the influence of the use of home bleaching agents but the hardness of the flowable bulk-fill composite resin.

Samples were stored in a dessicator placed in a non-CO2 incubator at $37^{\circ} \mathrm{C}$ for 24 hours so that the process of polymerization of bulk-fill flowable composite resin was perfect. The artificial saliva composition used in this study consisted of $\mathrm{NaCl}(6.7 \mathrm{~g} / \mathrm{I}), \mathrm{NaHCO} 3(1.50 \mathrm{~g} /$ I), $\mathrm{KCl}(1.20 \mathrm{~g} / \mathrm{l}), \mathrm{Na} 2 \mathrm{HPO} 4(0.26 \mathrm{~g} / \mathrm{l})$, $\mathrm{KH} 2 \mathrm{PO} 4(0.20 \mathrm{~g} / \mathrm{I})$ and $\mathrm{KSCN}(0.33 \mathrm{~g} / \mathrm{I})$ with $\mathrm{a} \mathrm{pH}$ of 7.59 .

The results of the study showed that there were significant differences in the surface hardness of flowable composite-fill composite resin which were treated with home bleaching using hydrogen peroxide. But not with flowable bulk-fill composite resins treated with home bleaching using carbamide peroxide ${ }^{[17]}$.

The surface hardness of flowable bulk-fill composite resins in the group treated with home bleaching using hydrogen peroxide (29.40HV / VHN) was significantly lower than that of untreated flowable bulk-fill composite resins 
(32.9 HV / VHN). However, not with composite resin that is treated with home bleaching using carbamide peroxide. This might be due to the higher content of $\mathrm{H} 2 \mathrm{O} 2$ in home bleaching agents of hydrogen peroxide so that it can affect the surface hardness of flowable bulk-fill composite resins $(32.20 \mathrm{HV} / \mathrm{VHN})^{[8]}$.

In the process of teeth whitening (bleaching) using hydrogen peroxide $(\mathrm{H} 2 \mathrm{O} 2)$ occurs the breakdown of $\mathrm{H} 2 \mathrm{O} 2$ compounds into $\mathrm{HO} 2$ (peryhydroxyl) which is a strong free radical and $\mathrm{O} 2$ as a weak free radical. When $\mathrm{HO} 2$ is formed in large numbers, these free radicals will react with the unsaturated bonds of the electron bonds in the enamel. This causes interference with electron conjugation and changes in energy absorption in organic molecules, in addition to causing changes in the molecular weight of dental organic matter which reflects specific light wave changes in materials with lower molecular weight and molecules that reflect light, thus forming organic molecules with lighter color ${ }^{[18]}$. Tooth whitening agents used can reduce the hardness of composite restorations, Bailey in 1992, and Hannig in 2006 explained that hydrogen peroxide is oxidized and produces free radicals ${ }^{[19]}$. Hydrogen peroxide breaks down into $\mathrm{H}+$ ions which are unstable free radicals. Free radicals that are formed will interact with organic composite molecules which are the matrix and break the cyclic carbon bonds in Bis-GM ${ }^{[20]}$.

The carbon double bond in the cyclic chain will be broken down into one single chain. This process continues until total oxidation occurs. This condition causes the cyclic bis-GMA to weaken and be degraded so that the composite hardness will be reduced ${ }^{[21]}$.

In addition, free radicals also interfere with the bonding of the coupling agent (coupling agent). Peryhydroxyl which is a weak acid will break the siloxane bond into a silanol bond. Breaking the siloxane bond between the coupling agent and the filler will cause the release of the filler particles and decrease the surface hardness of the composite resin ${ }^{[20]}$.

\section{CONCLUSION}

The conclusion of this research is that there are differences in surface hardness of bulk-fill flowable composite resin after home bleaching using hydrogen peroxide and cabamide peroxide. The results show that hydrogen peroxide home bleaching agent can significantly reduce the surface hardness of bulk-fill flowable composite resins.

\section{Conflict of interest: None}

Source of Funding: Self-Funding

\section{Ethical Clearance :}

This study was approved by the Universitas Airlangga, Faculty of Dental Medicine Health Research Ethical Clearance Commission

\section{REFERENCES}

I. Annusavice K, Shen C, Rawls H. Phillip's Science of Dental Materials. I3th Ed. China: Elsevier Saunders Inc.; 2013.

2. Imanda Harahap K, Yudhit A, Revita Sari F. Effect of Bench Time on Surface Hardness of Nanofiller Composite Resin. Int J Dent Sci Res 2019;7(I):18-20.

3. Yendriwati, Sinaga RM, Dennis D. Increase of enamel hardness score after cow milk immersion of demineralized tooth: An in vitro study. World J Dent 2018;9(6):439-43.

4. Benetti A, Havndrup-Pedersen A, Pedersen C, Honore DM, Pallesen C. Bulk-Fill Resin Composites: Polymerization Contraction, Depth of Cure, and Gap Formation. Oper Dent 20I5;40(2): 190-200.

5. Farahanny W, Dennis D, Sihombing D. Fracture resistance of various bulk-fill composite resins in class II MOD cavity on premolars: An In Vitro study. World J Dent 2019;10(3): 166-9.

6. Garcia D, Yaman P, Dennison J, Neiva G. Polymerization Shrinkage and Depth of Cure of Bulk Fill Flowable Composite Resins. Oper Dent 20I4;39(4):44I-8.

7. Rahmawati $D$, Retno Indrawati $R$, Roestamadji RI, Setiawatie EM, Yuliati A, Bramantoro T. Osteogenic ability of combined hematopoetic stem cell, hydroxyapatite graft and platelet rich fibrin on rats (Rattus novergicus). J Krishna Inst Med Sci Univ 2017;6(4):88-95.

8. Greenwall L. Bleaching Teqhniques in Restorative Dentistry. 2th Ed. New York: Taylor \& Francis Group.; 2014.

9. Suprastiwi E. Penggunaan Karbamid Peroksida sebagai Pemutih Gigi. Indones J Dent 2005; I2(3): 139-45.

10. Nugraheni T, Nuryono $N$, Sunarintyas $S$, Mulyawati E. Composite resin shear bond strength on bleached dentin increased by 35\% sodium ascorbate application. Dent J (Majalah Kedokt Gigi) 2017;50(4): 178.

II. Nugroho JJ, Natsir N, Trilaksana AC, Rovani CA, Atlanta MM. The increase of tooth enamel surface hardness after application blood cockle shells (Anadara granosa) paste as remineralization agent. Int J Appl Pharm [Internet] 2019;1।:26-9.

12. Marlow J, Davy SK, Shaffer M, Haris A, Bell JJ. Bleaching and recovery of a phototrophic bioeroding sponge. Coral Reefs [Internet] 
2018;37(2):565-70.

13. Istianah Ekoningtyas, SA Benyamin B. Perbedaan Pengaruh Hidrogen Peroksida 35\% dan Karbamid Peroksida 35\% Terhadap Mikroleakage Pada Resin Komposit Nanohybrid. ODONTO Dent J 2015;2(I):204.

14. Handayani TM, Nugroho R, Hidayati L, Fatmawati DWA, Sumono A. Effects of glycerin application on the hardness of nanofilled composite immersed in tamarind soft drinks. Dent J (Majalah Kedokt Gigi) 2019;52(2):95.

15. Gupta R, Tomer A, Kumari A, Mullick S, Dubey S. Bulkfill Flowable Composite Resins A Review. Int J Appl Dent Sci 2017;3(2):38-40.

16. Hibbeler R. Resistance of Materials. 3rd Ed. Rio de Janeiro: Technical and Scientific Books Publisher; 2000.

17. Giacomelli F, Cristiano G, Spinelli A. Behavior of a Co-Cr-Mo Biomaterial in Simulated Body Fluid Solution Studied by Electrochemical and Surface Analysis Techniques,. J Braz Chem Soc 2004; I5(4):54I-7.

18. Gandaatmaja D, Mulyawati E, Halim H, Widyastuti W. Pengaruh Perbedaan Jenis Resin Komposit dan Konsentrasi Bahan Hidrogen Peroksida Pada Perubahan Kekasaran Permukaan Resin Komposit Setelah Prosedur In Office Bleaching. J Kedokt Gigi 2010; I(3):129-34.

19. Hannig C, Duong S, Becker K, Brunner E, Kahler E, Attin T. Effect Of Bleaching on Subsurface Micro-Hardness Of Composite and Polyacid Modified Composite. Dent Mater 2007;23(2):198-203.

20. Polydorou O, Hellwig E, Auschill T. The Effect of At-Home Bleaching on The Microhardness of Six Esthetic Restorative Materials. J Am Dent Assoc 2007; I 38(7):978-84.

21. Ferracane J. Hygroscopic and Hydrolitic Effects in Dental Polymer Networks. Dent Mater 2006;22(3):2II-22. 